Cochrane Database of Systematic Reviews

\title{
Aural toilet (ear cleaning) for chronic suppurative otitis media (Protocol)
}

Bhutta MF, Head K, Chong LY, Tu N, Schilder AGM, Burton MJ, Brennan-Jones CG

Bhutta MF, Head K, Chong LY, Tu N, Schilder AGM, Burton MJ, Brennan-Jones CG.

Aural toilet (ear cleaning) for chronic suppurative otitis media.

Cochrane Database of Systematic Reviews 2018, Issue 6. Art. No.: CD013057.

DOI: 10.1002/14651858.CD013057.

www.cochranelibrary.com 


\section{TABLE OF CONTENTS}

HEADER . . . . . . . . . . . . . . . . . . . . . . . . . . . . . . . . . . . . . . . . 1

ABSTRACT . . . . . . . . . . . . . . . . . . . . . . . . . . . . . . . . . . . . . . 1

BACKGROUND . . . . . . . . . . . . . . . . . . . . . . . . . . . . . . . . . . . . . . 1

OBJECTIVES . . . . . . . . . . . . . . . . . . . . . . . . . . . . . . . . . . . . . . 3

METHODS . . . . . . . . . . . . . . . . . . . . . . . . . . . . . . . . . . . . . . 4

ACKNOWLEDGEMENTS . . . . . . . . . . . . . . . . . . . . . . . . . . . . . . . . . . . . . . . .

REFERENCES . . . . . . . . . . . . . . . . . . . . . . . . . . . . . . . . . . . . . . . . 9

ADDITIONAL TABLES . . . . . . . . . . . . . . . . . . . . . . . . . . . . . . . . . . . . . . . . . . . . .

APPENDICES . . . . . . . . . . . . . . . . . . . . . . . . . . . . . . . . . . . . . . . 11

CONTRIBUTIONS OF AUTHORS . . . . . . . . . . . . . . . . . . . . . . . . . . . . . . . . . . . . . . . .

DECLARATIONS OF INTEREST . . . . . . . . . . . . . . . . . . . . . . . . . . . . . . . . . 24

SOURCES OF SUPPORT . . . . . . . . . . . . . . . . . . . . . . . . . . . . . . . . . . . . . . . . . . . 
[Intervention Protocol]

\title{
Aural toilet (ear cleaning) for chronic suppurative otitis media
}

\author{
Mahmood F Bhutta ${ }^{1}$, Karen Head ${ }^{2}$, Lee-Yee Chong ${ }^{2}$, Nathan Tu$^{3}$, Anne GM Schilder ${ }^{4}$, Martin J Burton ${ }^{5}$, Christopher G Brennan- \\ Jones $^{6}$ \\ ${ }^{1}$ Department of Otolaryngology, West Wing - John Radcliffe Hospital, Oxford, UK. ${ }^{2}$ Cochrane ENT, Nuffield Department of Surgical \\ Sciences, University of Oxford, Oxford, UK. ${ }^{3}$ Department of Otolaryngology, University of Southern California, Los Angeles, USA. \\ ${ }^{4}$ evidENT, Ear Institute, Faculty of Brain Sciences, University College London, London, UK. ${ }^{5}$ UK Cochrane Centre, Oxford, UK. \\ ${ }^{6}$ Telethon Kids Institute, The University of Western Australia, Perth, Australia
}

Contact address: Mahmood F Bhutta, Department of Otolaryngology, West Wing - John Radcliffe Hospital, Headley Way, Oxford, OX3 9DU, UK. m.bhutta@doctors.org.uk.

Editorial group: Cochrane ENT Group.

Publication status and date: New, published in Issue 6, 2018.

Citation: Bhutta MF, Head K, Chong LY, Tu N, Schilder AGM, Burton MJ, Brennan-Jones CG. Aural toilet (ear cleaning) for chronic suppurative otitis media. Cochrane Database of Systematic Reviews 2018, Issue 6. Art. No.: CD013057. DOI: 10.1002/14651858.CD013057.

Copyright (C) 2018 The Cochrane Collaboration. Published by John Wiley \& Sons, Ltd.

\section{A B S T R A C T}

This is a protocol for a Cochrane Review (Intervention). The objectives are as follows:

To assess the effects of aural toilet procedures for people with chronic suppurative otitis media.

\section{B A C K G R O U N D}

This is one of a suite of Cochrane Reviews evaluating the comparative effectiveness of non-surgical interventions for CSOM using topical antibiotics, topical antibiotics with corticosteroids, systemic antibiotics, topical antiseptics and aural toileting (ear cleaning) methods (Table 1).

This review will compare the effectiveness of aural toileting (ear cleaning) against other methods of aural toileting or placebo/no treatment for CSOM.

\section{Description of the condition}

Chronic suppurative otitis media (CSOM), which is also often referred to as chronic otitis media (COM), is a chronic inflammation and infection of the middle ear and mastoid cavity, charac- terised by ear discharge (otorrhoea) through a perforated tympanic membrane.

The predominant symptoms of CSOM are ear discharge and hearing loss. Ear discharge can be persistent or intermittent, and many sufferers find it socially embarrassing (Orji 2013). Some patients also experience discomfort or earache. Most patients with CSOM experience temporary or permanent hearing loss with average hearing levels typically between 10 and 40 decibels (Jensen 2013). The hearing loss can be disabling, and it can have an impact on speech and language skills, employment prospects, and on children's psychosocial and cognitive development, including academic performance (Elemraid 2010; Olatoke 2008; WHO 2004). Consequently, quality of life can be affected. CSOM can also progress to serious complications in rare cases (and more often when cholesteatoma is present): both extracranial complications (such as mastoid abscess, postauricular fistula and facial palsy) and intracranial complications (such as otitic meningitis, lateral sinus 
thrombosis and cerebellar abscess) have been reported (Dubey 2007; Yorganc lar 2013).

CSOM is estimated to have a global incidence of 31 million episodes per year, or 4.8 new episodes per 1000 people (all ages), with $22 \%$ of cases affecting children under five years of age (Monasta 2012; Schilder 2016). The prevalence of CSOM varies widely between countries, but it disproportionately affects people at socio-economic disadvantage. It is rare in high-income countries, but common in many low- and middle-income countries (Mahadevan 2012; Monasta 2012; Schilder 2016; WHO 2004).

\section{Definition of disease}

There is no universally accepted definition of CSOM. Some define CSOM in patients with a duration of otorrhoea of more than two weeks but others may consider this an insufficient duration, preferring a minimum duration of six weeks or more than three months (Verhoeff 2006). Some include diseases of the tympanic membrane within the definition of CSOM, such as tympanic perforation without a history of recent ear discharge, or the disease cholesteatoma (a growth of the squamous epithelium of the tympanic membrane).

In accordance with a consensus statement, here we will use CSOM only to refer to tympanic membrane perforation, with intermittent or continuous ear discharge (Gates 2002). We will use a duration of otorrhoea of two weeks as an inclusion criterion, in accordance with the definition used by the World Health Organization, but we will use subgroup analyses to explore whether this is a factor that affects observed treatment effectiveness (WHO 2004).

Many people affected by CSOM do not have good access to modern primary healthcare, let alone specialised ear and hearing care, and in such settings health workers may be unable to view the tympanic membrane to definitively diagnose CSOM. It can also be difficult to view the tympanic membrane when the ear discharge is profuse. Therefore we will also include, as a subset for analysis, studies where participants have had chronic ear discharge for at least two weeks, but where the diagnosis is unknown.

\section{At-risk populations}

Some populations are considered to be at high risk of CSOM. There is a high prevalence of disease among Indigenous people such as the Aboriginal and Torres Strait Islander Australian, Native American and Inuit populations. This is likely due to an interplay of factors, including socio-economic deprivation and possibly differences resulting from population genetics (Bhutta 2016). Those with primary or secondary immunodeficiency are also susceptible to CSOM. Children with craniofacial malformation (including cleft palate) or chromosomal mutations such as Down syndrome are prone to chronic non-suppurative otitis media ('glue ear'), and by extrapolation may also be at greater risk of suppurative otitis media. The reasons for this association with craniofacial malformation are not well understood, but may include altered function of the Eustachian tube, coexistent immunodeficiency, or both. These populations may be less responsive to treatment and more likely to develop CSOM, recurrence or complications.

Children who have a grommet (ventilation tube) in the tympanic membrane to treat glue ear or recurrent acute otitis media may be more prone to develop CSOM; however, their pathway to CSOM may differ and therefore they may respond differently to treatment. Children with grommets who have chronic ear discharge meeting the CSOM criteria are therefore considered to be a separate highrisk subgroup (van der Veen 2006).

\section{Treatment}

Treatments for CSOM may include topical antibiotics (administered into the ear) with or without steroids, systemic antibiotics (given either by mouth or by injection), topical antiseptics and ear cleaning (aural toileting), all of which can be used on their own or in various combinations. Whereas primary healthcare workers or patients themselves can deliver some treatments (for example, some aural toileting and antiseptic washouts), in most countries antibiotic therapy requires prescription by a doctor. Surgical interventions are an option in cases where complications arise or in patients who have not responded to pharmacological treatment; however, there is a range of practice in terms of the type of surgical intervention that should be considered and the timing of the intervention. In addition, access to or availability of surgical interventions is setting-dependent. This series of Cochrane Reviews will therefore focus on non-surgical interventions. In addition, most clinicians consider cholesteatoma to be a variant of CSOM, but acknowledge that it will not respond to non-surgical treatment (or will only respond temporarily) (Bhutta 2011). Therefore, people with cholesteatoma will not be included in these reviews.

\section{Description of the intervention}

Aural toileting is an umbrella term used to describe the process of manually cleaning the ear. Techniques used may include dry mopping ('wicking', with cotton wool or tissue paper), suction clearance (typically under a microscope) or irrigation (using manual or automated syringing). Dry mopping may be effective in removing mucopurulent discharge, but less effective in removing epithelial debris or thick pus compared to irrigation or microsuction. Aural toileting can be used alone or in addition to other treatments for CSOM, such as antibiotics or topical antiseptics.

The technique and frequency of toileting may have an impact on its effectiveness. It is possible that dry mopping in the community is more effective because it can be delivered frequently, or it may be that less frequent suctioning by a specialist using a microscope is more effective because debris and pus are comprehensively removed. For these reasons, we will consider the different aural toileting methods as separate subgroups and pooling will only occur if there is no evidence of a difference in effect. 


\section{How the intervention might work}

In aural toileting the ear canal is manually cleaned to remove the pathogenic bacteria and inflammatory mediators that contribute to inflammation, to allow the tympanic membrane to be visualised for diagnosis, and to facilitate the delivery of topical interventions such as antibiotics or antiseptics to the target area to improve their effectiveness.

There have been reports of pain, bleeding and dizziness and/or vertigo with aural toileting (Addams-Williams 2010; Gray 1988). With suction techniques there is also the potential for noise-induced hearing loss, although no lasting effects have been observed (Addams-Williams 2010).

\section{Why it is important to do this review}

Aural toileting is often used prior to other interventions such as topical antiseptics or antibiotics, but it is not known what role aural toileting alone plays in disease resolution or whether there are important differences in the effectiveness of different techniques. In addition, the use of aural toileting may influence clinical decisions regarding which other treatments to use (for example, systemic or topical treatment). Therefore the effectiveness of aural toilet as an adjunctive treatment is also an important question. Aural toileting is a potentially low-cost treatment that is accessible in most settings; it is even possible to perform some forms of aural toileting, such as dry mopping, without medical support. The effectiveness of such interventions thus has implications for how and where treatment for CSOM is provided.

\section{O B J E C T I VES}

To assess the effects of aural toilet procedures for people with chronic suppurative otitis media.

\section{METHODS}

\section{Criteria for considering studies for this review}

\section{Types of studies}

We will include studies with the following design characteristics:

- Randomised controlled trials (including cluster-randomised trials where the unit of randomisation is the setting or operator) and quasi-randomised trials.

- Patients were followed up for at least one week.

We will exclude studies with the following design characteristics:
- Cross-over trials, because CSOM is not expected to be a stable chronic condition. Unless data from the first phase are available, we will exclude such studies.'

\section{Types of participants}

We will include studies with patients (adults and children) who had:

- chronic ear discharge of unknown cause; or

- chronic suppurative otitis media.

We will define patients with chronic ear discharge as patients with at least two weeks of ear discharge, where the cause of the discharge was unknown.

We will define patients with chronic suppurative otitis media (CSOM) as patients with:

- chronic or persistent ear discharge for at least two weeks; and

- a perforated tympanic membrane.

We will not exclude any populations based on age, risk factors (cleft palate, Down syndrome), ethnicity (e.g. Australian Aboriginal or Torres Strait Islanders) or the presence of ventilation tubes (grommets). Where available, we will record these factors in the patient characteristics section during data extraction from the studies. If any of the included studies mostly recruited these patients ( $80 \%$ or more), we will analyse them in a subgroup analysis (see Subgroup analysis and investigation of heterogeneity).

We will exclude studies where the majority (more than 50\%) of participants:

- had an alternative diagnosis to CSOM (e.g. otitis externa);

- had underlying cholesteatoma;

- had ear surgery within the last six weeks.

We will not include studies designed to evaluate interventions in the immediate peri-surgical period, which are focused on assessing the impact of the intervention on the surgical procedure or outcomes.

\section{Types of interventions}

\section{Intervention}

All aural toileting methods, frequencies and durations, including but not limited to the following:

- Dry mopping ('wicking'): with cotton bud; Jobson-Horne or other ear probe wrapped in cotton wool; or tissue spears (rolled up tissue papers).

- Irrigation of the external auditory canal using a syringe or similar device. Different solutions (antiseptics versus normal water/saline) and types of irrigation instrument (e.g. manual syringe versus automated Propulse) have been described. Irrigation may be followed by dry mopping or vice versa. 
- Microsuction of the external auditory canal to remove discharge.

\section{Comparisons}

The following are the comparators:

- Placebo, no treatment

- Another method or aural toileting.

There are three potential scenarios for analysis:

- Aural toileting as a stand-alone treatment: studies where all participants received no additional treatment or another form of aural toileting (e.g. a study comparing microsuction plus daily dry mopping versus daily dry mopping).

- Aural toileting as an add-on to antiseptics: this will include studies where all participants also used a daily antiseptic, with or without another form of aural toileting procedure.

- Aural toileting as an add-on to topical/systemic antibiotics: studies where all participants received topical or systemic antibiotics, with or without another form of aural toileting or antiseptics.

Many comparison pairs are possible in this review. The main comparisons of interest that we will summarise and present in the 'Summary of findings' table will be:

- aural toileting as a main (single) therapy versus placebo or no intervention;

- aural toileting versus placebo or no intervention, where both arms also received topical antibiotics and/or systemic antibiotics as an add-on therapy; and

- aural toileting versus placebo or no intervention, where both arms also received topical antiseptics as an add-on therapy.

\section{Types of outcome measures}

We will analyse the following outcomes in the review, but we will not use them as a basis for including or excluding studies. We will extract and report data from the longest available followup for all outcomes.

\section{Primary outcomes}

- Resolution of ear discharge or 'dry ear' (whether otoscopically confirmed or not), measured at:

- between one week and up to two weeks;

$\circ$ two weeks to up to four weeks; and

$\circ$ after four weeks.

- Health-related quality of life using a validated instrument for CSOM (e.g. Chronic Otitis Media Outcome Test (COMOT)-12 (Phillips 2014a; Phillips 2014b; van Dinther 2015), Chronic Otitis Media Outcome Test (COMOT)-15

(Baumann 2011), Chronic Ear Survey (CES) (Nadol 2000).

- Ear pain (otalgia) or discomfort or local irritation.

\section{Secondary outcomes}

- Hearing, measured as the pure-tone average of air conduction thresholds across four frequencies tested $(500 \mathrm{~Hz}$, $1000 \mathrm{~Hz}, 2000 \mathrm{~Hz}$ and $4000 \mathrm{~Hz}$ ) of the affected ear. If this is not available, we will report the pure-tone average of the thresholds measured.

- Serious complications, including intracranial complications (such as otitic meningitis, lateral sinus thrombosis and cerebellar abscess) and extracranial complications (such as mastoid abscess, postauricular fistula and facial palsy), and death.

- Adverse events: dizziness/vertigo/balance problems.

- Adverse events: ear bleeding.

\section{Search methods for identification of studies}

The Cochrane ENT Information Specialist will conduct systematic searches for randomised controlled trials and controlled clinical trials. There will be no language, publication year or publication status restrictions. We may contact original authors for clarification and further data if trial reports are unclear and we will arrange translations of papers where necessary.

\section{Electronic searches}

Published, unpublished and ongoing studies will be identified by searching the following databases from their inception:

- the Cochrane Register of Studies ENT Trials Register

(search via CRS Web to date);

- the Cochrane Central Register of Controlled Trials

(CENTRAL) (search via CRS Web to date);

- Ovid MEDLINE(R) Epub Ahead of Print, In-Process \& Other Non-Indexed Citations, Ovid MEDLINE(R) Daily and Ovid MEDLINE(R) (1946 to present);

- Ovid EMBASE (1974 to date);

- EBSCO CINAHL (1982 to date);

- LILACS (search to date);

- KoreaMed (search to date);

- IndMed (search to date);

- PakMediNet (search to date);

- African Index Medicus (search to date);

- Web of Knowledge, Web of Science (1945 to date);

- ClinicalTrials.gov, www.clinicaltrials.gov (search via the Cochrane Register of Studies to date);

- World Health Organization (WHO) International Clinical Trials Registry Platform (ICTRP) (search to date);

- ISRCTN, www.isrctn.com (search to date).

The subject strategies for databases are detailed in Appendix 1. The strategy has been designed to identify all relevant studies for a suite of reviews on various interventions for chronic otitis media (Bhutta 2018; Brennan-Jones 2018a; Brennan-Jones 2018b; 
Chong 2018a; Chong 2018b; Head 2018a; Head 2018b), with additional top-up searches for this review. Where appropriate, these will be combined with subject strategy adaptations of the highly sensitive search strategy designed by Cochrane for identifying randomised controlled trials and controlled clinical trials (as described in the Cochrane Handbook for Systematic Reviews of Interventions Version 5.1.0, Box 6.4.b. (Handbook 2011)).

\section{Searching other resources}

We will scan the reference lists of identified publications for additional trials and contact trial authors if necessary. In addition, the Information Specialist will search Ovid MEDLINE to retrieve existing systematic reviews relevant to this systematic review, so that we can scan their reference lists for additional trials. The Information Specialist will also run non-systematic searches of Google Scholar to retrieve grey literature and other sources of potential trials.

\section{Data collection and analysis}

\section{Selection of studies}

At least two review authors (KH/LYC) will independently screen all titles and abstracts of the references obtained from the database searches to identify potentially relevant studies. At least two review authors (KH/LYC) will evaluate the full text of each potentially relevant study to determine whether it meets the inclusion and exclusion criteria for this review.

We will resolve any differences by discussion and consensus, with the involvement of a third author for clinical and methodological input where necessary.

\section{Data extraction and management}

At least two review authors (KH/LYC/CBJ/MB) will independently extract data from each study using a standardised data collection form (see Appendix 2). Whenever a study has more than one publication, we will retrieve all publications to ensure complete extraction of data. Where there are discrepancies in the data extracted by different review authors, we will check these against the original reports and resolve differences by discussion and consensus, with the involvement of a third author or a methodologist where appropriate. We will contact the original study authors for clarification or for missing data whenever possible. If differences are found between publications of a study, we will contact the original authors for clarification. We will use data from the main paper(s) if no further information is found.

We will include key characteristics of the included studies, such as study design, setting (including location), year of study, sample size, age and sex of participants, and how outcomes were defined or collected in the studies. In addition, we will also collect baseline information on prognostic factors or effect modifiers (see Appendix 2). For this review, this will include the following information whenever available:

- duration of ear discharge at entry to the study;

- diagnosis of ear discharge (where known);

- number people who may be at higher risk of CSOM, including those with cleft palate or Down syndrome;

- ethnicity of participants including the number who are from Indigenous populations;

- number who have previously had ventilation tubes (grommets) inserted (and, where known, the number who have tubes still in place);

- number who have had previous ear surgery;

- number who have had previous treatments for CSOM (non-responders, recurrent versus new cases).

We will record concurrent treatments alongside the details of the interventions used. See the 'Data extraction form' in Appendix 2 for more details.

For the outcomes of interest to the review, we will extract the findings of the studies on an available case analysis basis, i.e. we will include data from all patients available at the time points based on the treatment randomised whenever possible, irrespective of compliance or whether patients had received the treatment as planned.

In addition to extracting pre-specified information about study characteristics and aspects of methodology relevant to risk of bias, we will extract the following summary statistics for each trial and each outcome:

- For continuous data: the mean values, standard deviations and number of patients for each treatment group. Where endpoint data are not available, we will extract the values for change from baseline. We will analyse data from disease-specific quality of life scales such as COMOT-12, COMOT-15 and CES as continuous data.

- For binary data: the number of participants experiencing an event and the number of patients assessed at the time point.

- For ordinal scale data: if the data appear to be approximately normally distributed or if the analysis that the investigators performed suggests parametric tests were appropriate, then we will treat the outcome measures as continuous data. Alternatively, if data are available, we plan to convert into binary data.

- Time-to-event outcomes: we are not expecting any outcomes to be measured as time-to-event data. However, if outcomes such as resolution of ear discharge are measured in this way, we will report the hazard ratios.

For resolution of ear discharge, we will extract the longest available data within the time frame of interest, defined as from one week up to (and including) two weeks (7 days to 14 days), from two weeks up to (and including) four weeks (15 to 28 days), and after four weeks (28 days or one month). 
For other outcomes, we will report the results from the longest available follow-up period.

\section{Extracting data for pain/discomfort and adverse effects}

For these outcomes, there will be variations in how studies have reported the outcomes. For example, some studies will report both 'pain' and 'discomfort' separately whereas others will not. Prior to the commencement of data extraction, we will agree and specify a data extraction algorithm for how data should be extracted.

We will extract data for serious complications as a composite outcome. If a study reports more than one complication and we cannot distinguish whether these occurred in one or more patients, we will extract the data with the highest incidence. This prevents double counting.

\section{Extracting data from figures}

Where values for primary or secondary outcomes are shown as figures within the paper, we will contact the study authors to try to obtain the raw values. When the raw values are not provided, we will extract information from the graphs using an online data extraction tool, using the best quality version of the relevant figures available.

\section{Assessment of risk of bias in included studies}

At least two review authors (KH/LYC/CBJ/MB) will independently assess the risk of bias of each included study. We will follow the guidance in the Cochrane Handbook for Systematic Reviews of Interventions (Handbook 2011), using the Cochrane 'Risk of bias' tool. With this tool we will assess the risk of bias as 'low', 'high' or 'unclear' for each of the following six domains:

- sequence generation;

- allocation concealment;

- blinding of participants, personnel and outcome assessment;

- incomplete outcome data;

- selective reporting;

- other sources of bias.

\section{Measures of treatment effect}

We will summarise the effects of dichotomous outcomes (e.g. proportion of patients with complete resolution of ear discharge) as risk ratios (RR) with confidence intervals (CIs). For the key outcomes that we will present in the 'Summary of findings' table, we will also express the results as absolute numbers based on the pooled results and compared to the assumed risk. We also plan to calculate the number needed to treat to benefit (NNTB) using the pooled results. The assumed baseline risk will typically be either (a) the median of the risks of the control groups in the included studies, this being used to represent a 'medium-risk population' or, alternatively, (b) the average risk of the control groups in the included studies, which is used as the 'study population' (Handbook 2011). If a large number of studies are available, and where appropriate, we also plan to present additional data based on the assumed baseline risk in (c) a low-risk population and (d) a highrisk population.

For continuous outcomes, we will express treatment effects as a mean difference (MD) with standard deviation (SD). If different scales are used to measure the same outcome we will use the standardised mean difference (SMD) and we will provide a clinical interpretation of the SMD values.

\section{Unit of analysis issues}

\section{Cross-over studies}

This review will not use data from phase II of cross-over studies.

The ear as the unit of randomisation: within-patient randomisation in patients with bilateral ear disease

For data from studies where 'within-patient' randomisation was used (i.e. studies where both ears (right versus left) were randomised) the analyses will adjust for the paired nature of the data (Elbourne 2002; Stedman 2011), as outlined in section 16.4 of the Cochrane Handbook for Systematic Reviews of Interventions (Handbook 2011).

\section{The ear as the unit of randomisation: non-paired} randomisation in patients with bilateral ear disease

Some patients with bilateral disease may receive the same treatment in both ears, whereas others will receive a different treatment in each ear. We will not exclude these studies but we will only report the data if specific pairwise adjustments have been completed or if sufficient data can be obtained to be able to make adjustments.

\section{The patient as the unit of randomisation}

Some studies randomise by patient and those with bilateral CSOM will receive the same intervention for both ears. In some studies the results may be reported as a separate outcome for each ear (the total number of ears is used as the denominator in the analysis). The correlation of response between the left ear and right ear when given the same treatment is expected to be very high, and if both ears are counted in the analysis this is effectively a form of double counting, which may be especially problematic in smaller studies if the number of people with bilateral CSOM is unequal. We will not exclude these studies, but we will only report the results if the paper presents the data in such a way that we can include the data from each participant only once (one data point per participant) or if we have enough information to reliably estimate the effective 
sample size or inflated standard errors as presented in chapter 16.3 of the Cochrane Handbook for Systematic Reviews of Interventions (Handbook 2011). If this is not possible we will contact the authors for more information. If there is no response from the authors, then we will not include data from these studies in the analysis. If we find cluster-randomised trials by setting or operator, we will analyse these according to the methods in section 16.3 of the Cochrane Handbook for Systematic Reviews of Interventions (Handbook 2011).

\section{Dealing with missing data}

We will contact study authors via email whenever the outcome of interest is not reported, if the methods of the study suggest that the outcome had been measured. We will do the same if not all data required for meta-analysis are reported, unless the missing data are standard deviations. If standard deviation data are not available, we will approximate these using the standard estimation methods from $\mathrm{P}$ values, standard errors or 95\% CIs if these are reported, as detailed in the Cochrane Handbook for Systematic Reviews of Interventions (Handbook 2011). Where it is impossible to estimate these, we will contact the study authors.

Apart from imputations for missing standard deviations, we will not conduct any other imputations. We will extract and analyse data for all outcomes using the available case analysis method.

\section{Assessment of heterogeneity}

We will assess clinical heterogeneity (which may be present even in the absence of statistical heterogeneity) by examining the included studies for potential differences in the types of participants recruited, interventions or controls used, and the outcomes measured. We will not pool studies where the clinical heterogeneity makes it unreasonable to do so.

We will assess statistical heterogeneity by visually inspecting the forest plots and by considering the $\mathrm{Chi}^{2}$ test (with a significance level set at $\mathrm{P}$ value $<0.10$ ) and the $\mathrm{I}^{2}$ statistic, which calculates the percentage of variability that is due to heterogeneity rather than chance, with $\mathrm{I}^{2}$ values over $50 \%$ suggesting substantial heterogeneity (Handbook 2011).

\section{Assessment of reporting biases}

We will assess reporting bias as within-study outcome reporting bias and between-study publication bias.

\section{Outcome reporting bias (within-study reporting bias)}

We will assess within-study reporting bias by comparing the outcomes reported in the published report against the study protocol, whenever this can be obtained. If the protocol is not available, we will compare the outcomes reported to those listed in the methods section. If results are mentioned but not reported adequately in a way that allows analysis (e.g. the report only mentions whether the results were statistically significant or not), bias in a meta-analysis is likely to occur. We will try to find further information from the study authors. If no further information can be obtained, we will note this as being a high risk of bias. Where there is insufficient information to judge the risk of bias, we will note this as an unclear risk of bias (Handbook 2011).

\section{Publication bias (between-study reporting bias)}

We plan to create funnel plots if sufficient studies (more than 10) are available for an outcome. If we observe asymmetry of the funnel plot, we plan to conduct more formal investigation using the methods proposed by Egger 1997.

\section{Data synthesis}

We will conduct all meta-analyses using Review Manager 5.3 (RevMan 2014). For dichotomous data, we plan to analyse treatment differences as a risk ratio (RR) calculated using the MantelHaenszel methods. We plan to analyse time-to-event data using the generic inverse variance method.

For continuous outcomes, if all the data are from the same scale, we plan to pool mean values obtained at follow-up with change outcomes and report this as a MD. However, if the SMD has to be used as an effect measure, we will not pool change and endpoint data.

When statistical heterogeneity is low, random-effects versus fixedeffect methods yield trivial differences in treatment effects. However, when statistical heterogeneity is high, the random-effects method provides a more conservative estimate of the difference.

\section{Subgroup analysis and investigation of heterogeneity}

We will subgroup studies where most participants ( $80 \%$ or more) meet the criteria stated below in order to determine whether the effect of the intervention is different compared to other patients. Due to the risks of reporting and publication bias with unplanned subgroup analyses of trials, we will only analyse subgroups reported in studies if these were prespecified and stratified at randomisation. We plan to conduct subgroup analyses regardless of whether statistical heterogeneity is observed for studies that included patients identified as high risk (i.e. thought to be less responsive to treatment and more likely to develop CSOM, recurrence or complications) and patients with ventilation tubes (grommets). 'High risk' patients include Indigenous populations (e.g. Australian Aboriginal and Torres Strait Islanders, Native Americans and Inuit populations of Alaska, Canada and Greenland), people with craniofacial malformation (e.g. cleft palate), Down syndrome and people with known immunodeficiency.

We plan to present the main analyses of this review in the form of forest plots based on this main subgroup analysis. 
- For the high-risk group, this applies to the outcomes resolution of ear discharge (dry ear), quality of life, pain/ discomfort, development of complications and hearing loss.

For patients with ventilation tubes, this applies to the outcome resolution of ear discharge (dry ear) for the time point of four weeks or more because this group is perceived to be at lower risk of treatment failure and recurrence than other patient groups. If statistical heterogeneity is observed, we will also conduct subgroup analysis for the effect modifiers below. If there are statistically significant subgroup effects, we will present these subgroup analysis results as forest plots.

For this review, effect modifiers include:

- Diagnosis of CSOM: it is likely that some studies will include patients with chronic ear discharge but who have not had a diagnosis of CSOM. Therefore, we will subgroup studies where most patients ( $80 \%$ or more) meet the criteria for CSOM diagnosis in order to determine whether the effect of the intervention is different compared to patients where the precise diagnosis is unknown and inclusion into the study is based purely on chronic ear discharge symptoms.

- Duration of ear discharge: there is uncertainty about whether the duration of ear discharge prior to treatment has an impact on the effectiveness of treatment and whether more established disease (i.e. discharge for more than six weeks) is more refractory to treatment compared with discharge of a shorter duration (i.e. less than six weeks).

- Patient age: patients who are younger than two years old versus patients up to six years old versus adults. Patients under two years are widely considered to be more difficult to treat.

We will present the results as subgroups regardless of the presence of statistical heterogeneity based on the main types of aural toileting methods as follows:

- dry mopping;

- irrigation;

- microsuction.

This is because the different methods of aural toileting are expected to have different treatment effects and possible adverse effects due to their intensity (e.g. microsuction is thought to be a more intense method than dry mopping).

\section{Sensitivity analysis}

We plan to carry out sensitivity analyses to determine whether the findings are robust to the decisions made in the course of identifying, screening and analysing the trials. We plan to conduct sensitivity analysis for the following factors, whenever possible:

- Impact of model chosen: fixed-effect versus random-effects model.

- Risk of bias of included studies: excluding studies with high risk of bias (we will define these as studies that have a high risk of allocation concealment bias and a high risk of attrition bias (overall loss to follow-up of $20 \%$, differential follow-up observed)).

- Where there is statistical heterogeneity, studies that only recruited patients who had previously not responded to one of the treatments under investigation in the RCT. Studies that specifically recruited patients who did not respond to a treatment could potentially have reduced the relative effectiveness of an agent.

If any of these investigations finds a difference in the size of the effect or heterogeneity, we will mention this in the 'Effects of interventions' section and/or present the findings in a table.

\section{GRADE and 'Summary of findings' table}

Using the GRADE approach, at least two review authors $(\mathrm{KH} /$ LYC) will independently rate the overall quality of evidence using the GDT tool (http://www.guidelinedevelopment.org/) for the main comparison pairs listed in the Types of interventions section. The quality of evidence reflects the extent to which we are confident that an estimate of effect is correct and we will apply this in the interpretation of results. There are four possible ratings: 'high', 'moderate', 'low' and 'very low' (Handbook 2011). A rating of 'high' quality evidence implies that we are confident in our estimate of effect and that further research is very unlikely to change our confidence in the estimate of effect. A rating of 'very low' quality implies that any estimate of effect obtained is very uncertain.

The GRADE approach rates evidence from RCTs that do not have serious limitations as high quality. However, several factors can lead to the downgrading of the evidence to moderate, low or very low. The degree of downgrading is determined by the seriousness of these factors:

- study limitations (risk of bias);

- inconsistency;

- indirectness of evidence;

- imprecision;

- publication bias.

The 'Summary of findings' tables will present the following outcomes:

- resolution of ear discharge or 'dry ear':

$\circ$ at between one week and up to two weeks;

o after four weeks;

- health-related quality of life;

- ear pain (otalgia) or discomfort or local irritation;

- hearing;

- serious complications;

- adverse events: dizziness/vertigo/balance problems. 
This project was funded by the NHMRC Centre of Research Excellence in Ear and Hearing Health of Aboriginal and Torres Strait Islander Children (NHMRC CRE_ICHEAR). The contents of the publications arising from this work are solely the responsibility of the authors and do not reflect the views of NHMRC.

We are grateful to Mr Iain Swan for peer reviewing this protocol, and to consumer referee Joan Blakely for her helpful comments. We would also like to thank Dr. Adrian James, as Acting Coordinating Editor for Cochrane ENT, for his insightful comments and advice.
We would like to sincerely thank Jenny Bellorini and Samantha Cox from the Cochrane ENT team for their invaluable help, which has enabled the completion of this suite of protocols. We would also like to acknowledge the clinicians, researchers and consumers who contributed to a scoping consultation on this topic.

This project was supported by the National Institute for Health Research, via Cochrane Infrastructure, Cochrane Programme Grant or Cochrane Incentive funding to Cochrane ENT. The views and opinions expressed therein are those of the authors and do not necessarily reflect those of the Systematic Reviews Programme, NIHR, NHS or the Department of Health.

\section{REFERE N C ES}

\section{Additional references}

\section{Addams-Williams 2010}

Addams-Williams J, Howarth A, Phillipps JJ. Microsuction aural toilet in ENT outpatients: a questionnaire to evaluate the patient experience. European Archives of Otorhino-laryngology 2010;267(12):1863-6. DOI: 10.1007/ s00405-010-1326-8

Baumann 2011

Baumann I, Gerendas B, Plinkert PK, Praetorius M. General and disease-specific quality of life in patients with chronic suppurative otitis media--a prospective study. Health and Quality of Life Outcomes 2011;9:48. DOI: 10.1186/1477-7525-9-48

Bhutta 2011

Bhutta MF, Williamson IG, Sudhoff HH. Cholesteatoma. BMJ 2011;342:d1088. DOI: 10.1136/bmj.d1088

\section{Bhutta 2016}

Bhutta MF. Evolution and otitis media: a review, and a model to explain high prevalence in indigenous populations. Human Biology 2016;87(2):92-108.

\section{Bhutta 2018}

Bhutta MF, Head K, Chong LY, Tu N, Schilder AGM, Burton MJ, et al. Aural toilet for chronic suppurative otitis media. Cochrane Database of Systematic Reviews 2018, Issue 6.

Brennan-Jones 2018a

Brennan-Jones CG, Head K, Chong LY, Tu N, Burton MJ, Schilder AGM, et al. Topical antibiotics for chronic suppurative otitis media. Cochrane Database of Systematic Reviews 2018, Issue 6.

Brennan-Jones 2018b

Brennan-Jones CG, Chong LY, Head K, Tu N, Burton MJ, Schilder AGM, et al. Topical antibiotics with steroids for chronic suppurative otitis media. Cochrane Database of Systematic Reviews 2018, Issue 6.

\section{Chong 2018a}

Chong LY, Head K, Richmond P, Snelling T, Schilder AGM, Burton MJ, et al. Systemic antibiotics for chronic suppurative otitis media. Cochrane Database of Systematic Reviews 2018, Issue 6.

\section{Chong 2018b}

Chong LY, Head K, Richmond P, Snelling T, Schilder AGM, Burton MJ, et al. Topical versus systemic antibiotics for chronic suppurative otitis media. Cochrane Database of Systematic Reviews 2018, Issue 6.

Dubey 2007

Dubey SP, Larawin V. Complications of chronic suppurative otitis media and their management. Laryngoscope 2007;117 (2):264-7.

\section{Egger 1997}

Egger M, Davey Smith G, Schneider M, Minder C. Bias in meta-analysis detected by a simple, graphical test. $B M J$ 1997;315(7109):629-34.

\section{Elbourne 2002}

Elbourne DR, Altman DG, Higgins JP, Curtin F, Worthington HV, Vail A. Meta-analyses involving crossover trials: methodological issues. International Journal of Epidemiology 2002;31(1):140-9.

\section{Elemraid 2010}

Elemraid MA, Brabin BJ, Fraser WD, Harper G, Faragher $\mathrm{B}$, Atef $\mathrm{Z}$, et al. Characteristics of hearing impairment in Yemeni children with chronic suppurative otitis media: a case-control study. International Journal of Pediatric Otorhinolaryngology 2010;74(3):283-6.

\section{Gates 2002}

Gates GA, Klein JO, Lim DJ, Mogi G, Ogra PL, Pararella MM, et al. Recent advances in otitis media. 1. Definitions, terminology, and classification of otitis media. Annals of Otology, Rhinology \& Laryngology. Supplement 2002;188: 8-18.

\section{Gray 1988}

Gray RF, Nicolaides AR. Vertigo following aural suction: can it be prevented?. Clinical Otolaryngology 1988;13:2858 .

\section{Handbook 2011}

Higgins JPT, Green S (editors). Cochrane Handbook for Systematic Reviews of Interventions Version 5.1.0 
[updated March 2011]. The Cochrane Collaboration, 2011. Available from www.cochrane-handbook.org.

\section{Head 2018a}

Head K, Chong LY, Bhutta MF, Morris PS, Vijayasekaran S, Burton MJ, et al. Topical antiseptics for chronic suppurative otitis media. Cochrane Database of Systematic Reviews 2018, Issue 6.

\section{Head 2018b}

Head K, Chong LY, Bhutta MF, Morris PS, Vijayasekaran S, Burton MJ, et al. Antibiotics versus topical antiseptics for chronic suppurative otitis media. Cochrane Database of Systematic Reviews 2018, Issue 6.

\section{Jensen 2013}

Jensen RG, Koch A, Homøe P. The risk of hearing loss in a population with a high prevalence of chronic suppurative otitis media. International Journal of Pediatric Otorhinolaryngology 2013;77(9):1530-5. DOI: 10.1016/ j.ijporl.2013.06.025

\section{Mahadevan 2012}

Mahadevan M, Navarro-Locsin G, Tan HK, Yamanaka N, Sonsuwan N, Wang PC, et al. A review of the burden of disease due to otitis media in the Asia-Pacific. International Journal of Pediatric Otorhinolaryngology 2012;76(5):623-35. DOI: $10.1016 /$ j.ijporl.2012.02.031

\section{Monasta 2012}

Monasta L, Ronfani L, Marchetti F, Montico M, Vecchi Brumatti L, Bavcar A, et al. Burden of disease caused by otitis media: systematic review and global estimates. PloS One 2012;7(4):e36226.

\section{Nadol 2000}

Nadol JB Jr, Staecker H, Gliklich RE. Outcomes assessment for chronic otitis media: the Chronic Ear Survey. Laryngoscope 2000;110(3 Pt 3):32-5. DOI: $10.1097 /$ 00005537-200003002-00009

\section{Olatoke 2008}

Olatoke F, Ologe FE, Nwawolo CC, Saka MJ. The prevalence of hearing loss among schoolchildren with chronic suppurative otitis media in Nigeria, and its effect on academic performance. Ear, Nose, \& Throat Journal 2008; 87(12):E19.

\section{Orji 2013}

Orji F. A survey of the burden of management of chronic suppurative otitis media in a developing country. Annals of Medical and Health Sciences Research 2013;4(3):598-601. DOI: $10.4103 / 2141-9248.122126$

\section{Phillips 2014a}

Phillips JS, Yung MW. COMQ-12 scores in adult patients without chronic middle ear disease. Clinical Otolaryngology 2014;39(6):362-7. DOI: 10.1111/coa.12306

\section{Phillips 2014b}

Phillips JS, Haggard M, Yung M. A new health-related quality of life measure for active chronic otitis media (COMQ-12): development and initial validation. Otology \& Neurotology 2014;35(3):454-8. DOI: 10.1097/ mao.0000000000000205

\section{RevMan 2014 [Computer program]}

The Nordic Cochrane Centre, The Cochrane Collaboration. Review Manager (RevMan). Version 5.3. Copenhagen: The Nordic Cochrane Centre, The Cochrane Collaboration, 2014.

\section{Schilder 2016}

Schilder AG, Chonmaitree T, Cripps AW, Rosenfeld RM, Casselbrant ML, Haggard MP, et al. Otitis media. Nature Reviews Disease Primers 2016;2:16063. DOI: 10.1038/ nrdp. 2016.63

\section{Stedman 2011}

Stedman MR, Curtin F, Elbourne DR, Kesselheim AS, Brookhart MA. Meta-analyses involving cross-over trials: methodological issues. International Journal of Epidemiology 2011;40(6):1732-4. DOI: 10.1093/ije/dyp345

\section{van der Veen 2006}

van der Veen EL, Schilder AG, van Heerbeek N, Verhoeff M, Zielhuis GA, Rovers MM. Predictors of chronic suppurative otitis media in children. Archives of Otolaryngology--Head \& Neck Surgery 2006;132(10):1115-8. DOI: 10.1001/ archotol.132.10.1115

van Dinther 2015

van Dinther J, Droessaert V, Camp S, Vanspauwen R, Maryn Y, Zarowski A, et al. Validity and test-retest reliability of the Dutch Version of the Chronic Otitis Media Questionnaire 12 (COMQ-12). Journal of International Advanced Otology 2015;11(3):248-52. DOI: 10.5152/ iao.2015.1701

\section{Verhoeff 2006}

Verhoeff M, van der Veen EL, Rovers MM, Sanders EA, Schilder AG. Chronic suppurative otitis media: a review. International Journal of Pediatric Otorhinolaryngology 2006; 70(1):1-12.

\section{WHO 2004}

World Health Organization. Chronic Suppurative Otitis Media (CSOM): Burden of Illness and Management Options. Geneva, Switzerland: World Health Organization, 2004.

\section{Yorgana lar 2013}

Yorganc lar E, Yildirim M, Gun R, Bakir S, Tekin R, Gocmez C, et al. Complications of chronic suppurative otitis media: a retrospective review. European Archives of Oto-rhino-laryngology 2013;270(1):69-76. DOI: $10.1007 /$ s00405-012-1924-8

* Indicates the major publication for the study 


\section{ADDITIONAL TABLES}

Table 1. Table of Cochrane Reviews

\begin{tabular}{|c|c|c|c|c|c|}
\hline & $\begin{array}{l}\text { Topical antibiotics } \\
\text { with steroids }\end{array}$ & Topical antibiotics & $\begin{array}{l}\text { Systemic } \\
\text { antibiotics }\end{array}$ & Topical antiseptics & $\begin{array}{l}\text { Aural toileting (ear } \\
\text { cleaning) }\end{array}$ \\
\hline $\begin{array}{l}\text { Topical antibiotics } \\
\text { with steroids }\end{array}$ & Review CSOM-4 & & & & \\
\hline Topical antibiotics & Review CSOM-4 & Review CSOM-1 & & & \\
\hline Systemic antibiotics & Review CSOM-4 & Review CSOM-3 & Review CSOM-2 & & \\
\hline Topical antiseptics & Review CSOM-4 & Review CSOM-6 & Review CSOM-6 & Review CSOM-5 & \\
\hline Aural toileting & Review CSOM-4 & Not reviewed & Not reviewed & Not reviewed & Review CSOM-7 \\
\hline $\begin{array}{l}\text { Placebo (or no inter- } \\
\text { vention) }\end{array}$ & Review CSOM-4 & Review CSOM-1 & Review CSOM-2 & Review CSOM-5 & Review CSOM-7 \\
\hline
\end{tabular}

CSOM-1: Topical antibiotics for chronic suppurative otitis media (Brennan-Jones 2018a).

CSOM-2: Systemic antibiotics for chronic suppurative otitis media (Chong 2018a).

CSOM-3: Topical versus systemic antibiotics for chronic suppurative otitis media (Chong 2018b).

CSOM-4: Topical antibiotics with steroids for chronic suppurative otitis media (Brennan-Jones 2018b).

CSOM-5: Topical antiseptics for chronic suppurative otitis media (Head 2018a).

CSOM-6: Antibiotics versus topical antiseptics for chronic suppurative otitis media (Head 2018b).

CSOM-7: Aural toilet (ear cleaning) for chronic suppurative otitis media (Bhutta 2018).

\section{A P P E N D I C ES}

\section{Appendix I. Search strategies}

\begin{tabular}{|c|c|c|}
\hline CENTRAL (CRS Web) & MEDLINE (Ovid) & Embase (Ovid) \\
\hline $\begin{array}{l}1 \text { MESH DESCRIPTOR Otitis Media } \\
\text { EXPLODE ALL AND CENTRAL:TAR- } \\
\text { GET1061 } \\
2 \text { ("otitis media“ or OME):AB,EH,KW, } \\
\text { KY,MC,MH,TI,TO AND CENTRAL: } \\
\text { TARGET2347 } \\
3 \text { MESH DESCRIPTOR Tympanic Mem- } \\
\text { brane Perforation EXPLODE ALL AND }\end{array}$ & $\begin{array}{l}1 \text { exp Otitis Media/ } \\
2 \text { ("otitis media“" or OME).ab,ti. } \\
3 \text { exp Tympanic Membrane Perforation/ } \\
4 \text { exp Tympanic Membrane/ } \\
5 \text { ("ear drum*“ or eardrum* or tympanic). } \\
\text { ab,ti. } \\
64 \text { or } 5 \\
7 \text { (perforat* or hole or ruptur*).ab,ti. }\end{array}$ & $\begin{array}{l}1 \text { exp otitis media/ } \\
2 \text { ("otitis media“" or OME).ab,ti. } \\
3 \text { exp eardrum perforation/ } \\
4 \text { exp eardrum/ } \\
5 \text { ("ear drum*“ or eardrum* or tympanic). } \\
\text { ab,ti. } \\
64 \text { or } 5 \\
7 \text { (perforat* or hole or ruptur*).ab,ti. }\end{array}$ \\
\hline
\end{tabular}




\section{CENTRAL:TARGET71 \\ 4 MESH DESCRIPTOR Tympanic Mem- brane EXPLODE ALL AND CENTRAL: TARGET257 \\ 5 ("ear drum*“ or eardrum* or tympanic): AB,EH,KW,KY,MC,MH,TI,TO AND CENTRAL:TARGET967}

6 \#4 OR \#5 AND CENTRAL:TARGET967

7 (perforat* or hole or ruptur*):AB, $\mathrm{EH}, \mathrm{KW}, \mathrm{KY}, \mathrm{MC}, \mathrm{MH}, \mathrm{TI}, \mathrm{TO}$ AND CENTRAL:TARGET0

8 \#6 AND \#7 AND CENTRAL:TARGET0

9 \#1 OR \#2 OR \#3 OR \#8 AND CENTRAL:TARGET2386

10 MESH DESCRIPTOR Suppuration EXPLODE ALL AND CENTRAL:TARGET891

11 (suppurat* or pus or purulen* or discharg* or mucosal or otorrh* or otorh* or otoliquor* or active or weep* or wet or moist or discomfort or earach* $^{*}$ or mucopurulen*):AB,EH,KW,KY, MC,MH,TI,TO AND CENTRAL:TARGET90987

12 (pain):AB,TI,TO AND CENTRAL: TARGET87639

13 \#10 or \#11 or \#12 AND CENTRAL: TARGET165103

14 MESH DESCRIPTOR Chronic Disease EXPLODE ALL AND CENTRAL: TARGET11305

15 MESH DESCRIPTOR Recurrence EXPLODE ALL AND CENTRAL:TARGET10431

16 (chronic* or persist* or recurr* or repeat*):AB,EH,KW,KY,MC,MH,TI, TO AND CENTRAL:TARGET182517

17 \#14 OR \#15 OR \#16 AND CENTRAL:TARGET182523

18 \#9 AND \#17 AND \#13 AND CENTRAL:TARGET378

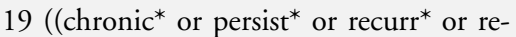
peat*) NEAR (ear or ears or aural) NEAR (suppurat* or pus or purulen* or discharg* or mucosal or otorrh* or otorh* or otoliquor* or active or weep* or wet or moist or mucopurulen* or pain* or dis-
86 and 7

91 or 2 or 3 or 4 or 8

10 exp Suppuration/ n

11 (suppurat* or pus or purulen* or dis-

charg* or mucosal or otorrh* or otorh*

or otoliquor* or active or weep* or moist or wet or mucopurulen* or discomfort or pain* or earach*).ab,ti

1210 or 11

13 exp Chronic Disease/

14 exp Recurrence/

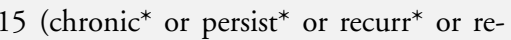
peat $\left.{ }^{*}\right) \cdot a b$, ti

1613 or 14 or 15

179 and 12 and 16

18 ((chronic or persist*) adj3 (ear or ears or aural) adj3 (suppurat* or pus or purulen* or discharg* or mucosal or otorrh* or otorh* or otoliquor* or active or weep* or wet or moist or mucopurulen* or pain* or discomfort)).ab,ti

19 CSOM.ab,ti.

20 exp Otitis Media, Suppurative/

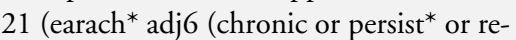
curr* or repeat*)).ab,ti

2217 or 18 or 19 or 20 or 21
86 and 7

91 or 2 or 3 or 8

10 exp suppuration/

11 (suppurat* or pus or purulen* or discharg* or mucosal or otorrh* or otorh* or otoliquor* or active or weep* or moist or wet or mucopurulen* or discomfort or pain* or earach*).ab,ti

1210 or 11

13 exp chronic disease/

14 exp recurrent disease/

15 (chronic* $^{*}$ or persist* or recurr* or repeat*).ab,ti.

1613 or 14 or 15

179 and 12 and 16

18 exp suppurative otitis media/

19 CSOM.ab,ti.

20 ((chronic or persist*) adj3 (ear or ears or aural) adj3 (suppurat* or pus or purulen* or discharg* or mucosal or otorrh* or otorh* or otoliquor* or active or weep* or wet or moist or mucopurulen* or pain* or discomfort or disease*)).ab,ti


curr* or repeat*)).ab,ti 2217 or 18 or 19 or 20 or 21 
comfort or disease*)):AB,EH,KW,KY,MC, MH,TI,TO AND CENTRAL:TARGET0 20 ((earach* near (chronic or persist* $^{*}$ or recurr* or repeat*))):AB,EH,KW,KY,MC, MH,TI,TO AND CENTRAL:TARGET3 21 MESH DESCRIPTOR Otitis Media, Suppurative EXPLODE ALL AND CENTRAL:TARGET104

22 (CSOM):AB,EH,KW,KY,MC,MH, TI,TO AND CENTRAL:TARGET88 23 \#20 OR \#21 OR \#22 OR \#18 OR \#19 AND CENTRAL:TARGET418
CINAHL (EBSCO)

S21 S17 OR S18 OR S19 OR S20

\#1 TOPIC: ("otitis media" or OME)

SSCI, S20 TX ((chronic or persist*) N3 (ear or Indexes=SCI-EXPANDED, A\&HCI, CPCI-S, CPCI-SSH, BKCI-S BKCI-SSH, ESCI, CCR-EXPANDED IC Timespan=All years

\#2 TOPIC: (("ear drum*“ or eardrum* or tympanic) AND (perforat* or hole or rup$\left.\operatorname{tur}^{*}\right)$ )

Indexes=SCI-EXPANDED,

SSCI, recurr* or repeat*))

A\&HCI, CPCI-S, CPCI-SSH, BKCI-S, S18 TX csom

BKCI-SSH, ESCI, CCR-EXPANDED, S17 S9 AND S12 AND S16

IC Timespan=All years

\#3 \#2 OR \#1

Indexes=SCI-EXPANDED,

SSCI, repeat*

A\&HCI, CPCI-S, CPCI-SSH, BKCI-S, S14 (MH "Recurrence“)

BKCI-SSH, ESCI, CCR-EXPANDED, S13 (MH "Chronic Disease")

IC Timespan=All years

S12 S10 OR S11

\#4 TOPIC: ((suppurat* or pus or purulen* or discharg* or mucosal or otorrh* or otorh* or otoliquor* or active or weep* or moist or wet or mucopurulen* or discomfort or pain* or earach*) AND (chronic* or persist* or recurr* or repeat $\left.{ }^{*}\right)$ ) Indexes=SCI-EXPANDED,

SSCI,

S11 TX suppurat* or pus or purulen* or discharg* or mucosal or otorrh* or otorh* or otoliquor* or active or weep* or moist or wet or mucopurulen* or discomfort or pain* or earach*) S10 (MH "Suppuration+")

A\&HCI, CPCI-S, CPCI-SSH, BKCI-S, S8 S6 AND S7

BKCI-SSH, ESCI, CCR-EXPANDED, S7 TX perforat* or hole or ruptur*

IC Timespan=All years

\#5 \#4 AND \#3

Indexes=SCI-EXPANDED,

SSCI,

S6 S4 OR S5

S5 TX "ear drum*“ or eardrum* or tym-

A\&HCI, CPCI-S, CPCI-SSH, BKCI-S, S4 (MH "Tympanic Membrane“)

BKCI-SSH, ESCI, CCR-EXPANDED, S3 (MH "Tympanic Membrane Perfora-

IC Timespan=All years

tion")

\#6 TOPIC: (((chronic or persist*) NEAR/

3 (ear or ears or aural) NEAR/3 (suppurat*
S2 TX "otitis media“" or OME

S1 (MH "Otitis Media+")

\section{Cochrane ENT Register (CRS Web)}

1 ("otitis media" or OME):AB,EH,KW, KY,MC,MH,TI,TO AND INREGISTER 2 ("'ear drum*“" or eardrum* or tympanic) ):AB,EH,KW,KY,MC,MH,TI,TO AND INREGISTER

3 (perforat* or hole or ruptur*):AB,EH, KW,KY,MC,MH,TI,TO AND INREGISTER

4 \#2 AND \#3 AND INREGISTER 5 \#4 OR \#1 AND INREGISTER

6 suppurat $^{*}$ or pus or purulen* or discharg* or mucosal or otorrh* or otorh* or otoliquor* or active or weep* or wet or moist or discomfort or ear$\mathrm{ach}^{*}$ or mucopurulen*):AB,EH,KW,KY, MC,MH,TI,TO AND INREGISTER 7 (pain):AB,TI,TO AND INREGISTER 8 \#6 OR \#7 AND INREGISTER

9 (chronic* or persist* or recurr* or repeat*):AB,EH,KW, KY,MC,MH,TI,TO AND INREGISTER 10 \#5 AND \#8 AND \#9 AND INREGISTER

11 (csom):AB,EH,KW,KY,MC,MH,TI, TO AND INREGISTER

12 (( (chronic* ${ }^{*}$ or persist ${ }^{*}$ or recurr* or repeat*) and (ear or ears or aural) and (suppurat* or pus or purulen* or discharg* or mucosal or otorrh* or otorh* or otoliquor* or active or weep* or wet or moist or mucopurulen* or pain* or discomfort or disease*) )):AB,EH,KW,KY,MC,MH,TI,TO AND INREGISTER 
or pus or purulen* or discharg* or mucosal or otorrh* or otorh* or otoliquor* or active or weep* or wet or moist or mucopurulen* or pain* or discomfort)))

Indexes=SCI-EXPANDED, SSCI, A\&HCI, CPCI-S, CPCI-SSH, BKCI-S, BKCI-SSH, ESCI, CCR-EXPANDED, IC Timespan=All years

\#7 TOPIC: ((earach* NEAR/3 (chronic or persist* ${ }^{*}$ or recurr* or repeat $\left.\left.{ }^{*}\right)\right)$ )

Indexes=SCI-EXPANDED, SSCI, A\&HCI, CPCI-S, CPCI-SSH, BKCI-S, BKCI-SSH, ESCI, CCR-EXPANDED, IC Timespan=All years

\#8 \#7 OR \#6 OR \#5

Indexes=SCI-EXPANDED, SSCI, A\&HCI, CPCI-S, CPCI-SSH, BKCI-S, BKCI-SSH, ESCI, CCR-EXPANDED, IC Timespan=All years
13 ((earach* and (chronic or persist* or recurr* or repeat*))):AB,EH,KW,KY,MC, MH,TI,TO AND INREGISTER

14 \#10 OR \#11 OR \#12 OR \#13 AND INREGISTER
ClinicalTrials.gov (CRS Web)

Search 1:

(chronic OR persistent OR recurrence OR recurrent) AND (suppuration OR pus OR discharge OR otorrhea or active OR mucopurulent)

AND

Condition: "Otitis Media“ OR OME

AND

Study type: interventional

\section{Search 2:}

(chronic OR persistent OR recurrence OR recurrent) AND (earache OR "ear ache“ OR" ear pain “OR” "ear discharge“ OR ”wet ear" OR "moist ear" OR "weeping ear")

AND

Study type: interventional

\section{Search 3:}

("ear drum" OR eardrum OR "tympanic membrane") AND (hole OR perforation OR rupture)

AND

Study type: interventional

\section{ICTRP (WHO Portal) Other}

otitis media AND chronic OR ear discharge OR earache OR wet ear OR weeping ear OR moist ear OR CSOM OR OME AND chronic OR tympanic membrane AND perforation OR eardrum AND hole OR eardrum AND perforation

\section{LILACS}

TW:"otitis media“ OR "TW:"ear discharge" OR TW:earache OR ((TW: eardrum OR TW:tympanic) AND (TW: perforation OR hole)) OR ((TW:wet OR moist OR weeping) AND TW:ear) AND:

Filter: Controlled Clinical Trial

\section{IndMed}

otitis media OR ear discharge OR csom OR earache OR wet ear OR tympanic membrane perforation OR eardrum hole OR wet ear OR weeping ear or moist ear OR OME

\section{PakMediNet}

otitis media | ear discharge | csom | earache | wet ear | tympanic membrane perforation | eardrum hole | wet ear | weeping ear

\section{African Index Medicus}

"otitis media"

OR

"ear discharge"

OR

CSOM

In addition to the strategy above (which will be applied to the six other reviews in this CSOM suite) we will also carry out the folowing additional top-up searches, which we will not combine with a randomised controlled trial filter and which will exclude the references retrieved with the above searches. 


\section{CENTRAL (CRS Web)}

1 MESH DESCRIPTOR Ear EXPLODE ALL AND CENTRAL:TARGET

2 MESH DESCRIPTOR Ear Diseases EXPLODE ALL AND CENTRAL:TARGET

3 (("otitis media" or OME)):AB,EH,KW, KY,MC,MH,TI,TO AND CENTRAL: TARGET

4 MESH DESCRIPTOR Tympanic Membrane Perforation EXPLODE ALL AND CENTRAL:TARGET

5 MESH DESCRIPTOR Tympanic Membrane EXPLODE ALL AND CENTRAL: TARGET

6 ("ear drum*” or eardrum* or tympanic): AB,EH,KW,KY,MC,MH,TI,TO AND CENTRAL:TARGET

7 \#5 OR \#6

AND

8 ((perforat* or hole or ruptur*).):AB, EH,KW,KY,MC,MH,TI,TO AND CENTRAL:TARGET

9 \#7 AND \#8

10 \#2 OR \# 1 OR \#3 OR \#4 OR \#9

11 MESH DESCRIPTOR Suppuration EXPLODE ALL AND CENTRAL:TARGET

12 (suppurat* or pus or purulen* or discharg* or mucosal or otorrh* or otorh* or otoliquor* or active or weep* or wet or moist or discomfort or earach* $^{*}$ or mucopurulen*):AB,EH,KW,KY, MC,MH,TI,TO AND CENTRAL:TARGET

13 (pain*):AB,TI AND CENTRAL:TARGET

14 \#12 OR \#11 OR \#13

15 \#14 AND \#10

16 MESH DESCRIPTOR Otitis Media, Suppurative EXPLODE ALL AND CENTRAL:TARGET

17 (CSOM or earach*):AB,EH,KW,KY, MC,MH,TI,TO AND CENTRAL:TARGET

18 (((ear or ears or aural) near (suppurat* or pus or purulen* or discharg* or mucosal or otorrh* or otorh* or otoliquor* or active or weep* or wet or moist or mucopurulen* or pain* or discomfort))):AB,EH,KW,KY,
Cochrane ENT Register (CRS Web)

MEDLINE (Ovid)

1 ("otitis media" or OME):AB,EH,KW, 1 exp Ear Diseases/ KY,MC,MH,TI,TO AND INREGISTER 2 exp Ear/

2 ("“ear drum*" or eardrum* or tympanic) 3 ("otitis media” or OME).ab,ti.

):AB,EH,KW,KY,MC,MH,TI,TO AND 4 exp Tympanic Membrane Perforation/

INREGISTER

5 exp Tympanic Membrane/

3 (perforat* or hole or ruptur*):AB,EH, 6 (“ear drum*” or eardrum* or tympanic). KW,KY,MC,MH,TI,TO AND INREG- ab,ti.

ISTER

4 \#2 AND \#3 AND INREGISTER

5 \#4 OR \# 1 AND INREGISTER

75 or 6

8 (perforat* or hole or ruptur*).ab,ti.

97 and 8

6 (suppurat* or pus or purulen* or dis-

charg* or mucosal or otorrh* or otorh*

or otoliquor* or active or weep* or

wet or moist or discomfort or ear-

ach* $^{*}$ or mucopurulen*):AB,EH,KW,KY,

MC,MH,TI,TO AND INREGISTER

7 (pain):AB,TI,TO AND INREGISTER

8 \#6 OR \#7 AND INREGISTER

9 (chronic* or

persist* or recurr* or repeat*):AB,EH,KW,

KY,MC,MH,TI,TO AND INREGISTER 10 \#5 AND \#8 AND \#9 AND INREGISTER

11 (csom or earach*):AB,EH,KW,KY,MC, MH,TI,TO AND INREGISTER

12 (((ear or ears or aural) NEAR (suppurat* or pus or purulen* or discharg* or mucosal or otorrh* or otorh* or otoliquor* or active or weep* ${ }^{*}$ or wet or moist or mucopurulen* or pain* or discomfort))):AB,EH,KW,KY, MC,MH,TI,TO AND INREGISTER 13 \#10 OR \#11 OR \#12 AND INREGISTER

14 (((ear or ears or aural) near (toilet* or care or hygiene or syring* or irrigat* or probe or swab* or wash* or clean* or clear* or suck or suction))):AB,EH,KW,KY,MC, MH,TI,TO AND INREGISTER

15 ((microsuction*

101 or 2 or 3 or 4 or 9

11 exp Suppuration/

12 (suppurat* or pus or purulen* or discharg* or mucosal or otorrh* or otorh* or otoliquor* or active or weep* or moist or wet or mucopurulen* or discomfort or pain* or earach*).ab,ti

1311 or 12

1410 and 13

15 exp Otitis Media, Suppurative/

16 (CSOM or earach*).ab,ti.

17 ((ear or ears or aural) adj3 (suppurat* or pus or purulen* or discharg* or mucosal or otorrh* or otorh* or otoliquor* or active or weep* or wet or moist or mucopurulen* or pain* or discomfort)).ab,ti

1814 or 15 or 16 or 17

19 ((ear or ears or aural) adj3 (toilet* or care or hygiene or syring* or irrigat* or probe or swab* $^{*}$ or wash* or clean* or clear* or suck or suction)).ab,ti

20 (microsuction* or propulse or "pro pulse").ab,ti.

21 (dry adj3 mop*).ab,ti.

22 ((cotton or tissue) adj3 (wool or bud or spear*)).ab,ti.

23 (jobson adj3 horn).ab,ti.

24 (chrome adj3 syring*).ab,ti.

propulse or "pro pulse")):AB,EH,KW,KY, 2618 and 25

MC,MH,TI,TO AND INREGISTER

16 ((dry near mop*)):AB,EH,KW,KY,MC, $\mathrm{MH}, \mathrm{TI}, \mathrm{TO}$ AND INREGISTER

17 (((cotton or tissue) near (wool or bud or spear*))):AB,EH,KW,KY,MC,MH,TI, TO AND INREGISTER 
MC,MH,TI,TO AND CENTRAL:TARGET

19 \#16 OR \#15 OR \#17 OR \#18

20 (((ear or ears or aural) near (toilet* or care or hygiene or syring* or irrigat* or probe or swab* or wash* or clean* or clear* or suck or suction))):AB,EH,KW,KY,MC, MH,TI,TO AND CENTRAL:TARGET

21 ((microsuction* or propulse or "pro pulse")):AB,EH,KW,KY,MC,MH, TI,TO AND CENTRAL:TARGET 22 ((dry near mop*)):AB,EH,KW,KY,MC, MH,TI,TO AND CENTRAL:TARGET

23 (((cotton or tissue) near (wool or bud or spear*))):AB,EH,KW,KY,MC,MH,TI, TO AND CENTRAL:TARGET

24 ((chrome near syring*)): $\mathrm{AB}, \mathrm{EH}, \mathrm{KW}$, KY,MC,MH,TI,TO AND CENTRAL: TARGET

25 ((jobson near horn)):AB,EH,KW,KY, MC,MH,TI,TO AND CENTRAL:TAR-

\section{GET}

26 \#20 OR \#21 OR \#22 OR \#23 OR \#24

OR \#25

27 \#26 AND \#19
18 ((jobson near horn)):AB,EH,KW,KY, MC,MH,TI,TO AND INREGISTER

19 ((chrome near syring*)): $\mathrm{AB}, \mathrm{EH}, \mathrm{KW}$, KY,MC,MH,TI,TO AND INREGISTER 20 \#15 OR \#14 OR \#16 OR \#17 OR \#19

OR \#18 AND INREGISTER

21 \#13 AND \#20 AND INREGISTER

\begin{tabular}{|c|c|}
\hline Embase (Ovid) & CINAHL (EBSCO) \\
\hline 1 exp ear disease/ & S25 S17 AND S24 \\
\hline 2 exp ear/ & S24 S 18 OR S 19 OR S 20 OR S 21 OR S22 \\
\hline 3 ("otitis media" or OME).ab,ti. & OR S23 \\
\hline 4 exp eardrum perforation/ & S23 TX (chrome N3 syring*) \\
\hline 5 exp eardrum/ & S22 TX (chrome N3 syring*) \\
\hline $\begin{array}{l}6 \text { (“ear drum*” or eardrum* or tympanic). } \\
\text { ab,ti. }\end{array}$ & $\begin{array}{l}\text { S21 TX ((cotton or tissue) N3 (wool or bud } \\
\text { or spear*)) }\end{array}$ \\
\hline 75 or 6 & S20 TX dry N3 mop*) \\
\hline $\begin{array}{l}8 \text { (perforat* or hole or ruptur*).ab,ti. } \\
97 \text { and } 8\end{array}$ & $\begin{array}{l}\text { S19 TX (microsuction* or propulse or "pro } \\
\text { pulse") }\end{array}$ \\
\hline 101 or 2 or 3 or 4 or 9 & S18 TX ((ear or ears or aural) N3 (toilet* \\
\hline 11 exp suppuration/ & or care or hygiene or syring* or irrigat* or \\
\hline $\begin{array}{l}12 \text { suppurat }^{*} \text { or pus or purulen* or dis- } \\
\text { charg* }^{*} \text { or mucosal or otorrh* or otorh* }\end{array}$ & $\begin{array}{l}\text { probe or swab* or wash* or clean* or clear* } \\
\text { or suck or suction)) }\end{array}$ \\
\hline or otoliquor* or active or weep* or moist & S17 S14 OR S15 OR S16 \\
\hline or wet or mucopurulen* or discomfort or & S16 TX ((ear or ears or aural) N3 (suppu- \\
\hline 1311 or 12 & cosal or otorrh* or otorh* or otoliquor* or \\
\hline 1410 and 13 & active or weep* or wet or moist or mucop- \\
\hline 15 exp suppura & urulen* or pain* or discomfort)) \\
\hline $16\left(\mathrm{CSOM}\right.$ or earach$\left.{ }^{*}\right) \cdot \mathrm{ab}, \mathrm{ti}$. & S15 TX CSOM or earach* \\
\hline
\end{tabular}

Aural toilet (ear cleaning) for chronic suppurative otitis media (Protocol)

Copyright $(2018$ The Cochrane Collaboration. Published by John Wiley \& Sons, Ltd. 
17 ((ear or ears or aural) adj3 (suppurat* or S14 S10 AND S13

pus or purulen* or discharg* or mucosal or S13 S11 OR S12

otorrh* or otorh* or otoliquor* or active or S12 TX suppurat* or pus or purulen* or

weep* or wet or moist or mucopurulen* or discharg* or mucosal or otorrh* or otorh*

pain* or discomfort)).ab,ti

1814 or 15 or 16 or 17

19 ((ear or ears or aural) adj3 (toilet* or care

or hygiene or syring* or irrigat* or probe or

swab* $^{*}$ or wash* or clean* or clear* or suck

or suction)).ab,ti

or otoliquor* or active or weep* or moist

or wet or mucopurulen* or discomfort or

pain* or earach*)

S11 (MH "Suppuration+")

20 (microsuction* or propulse or "pro pulse").ab,ti.

S10 S1 OR S2 OR S3 OR S4 OR S9

S9 S7 AND S8

S8 TX perforat* or hole or ruptur*

S7 S5 OR S6

21 (dry adj3 mop*).ab,ti.

22 ((cotton or tissue) adj3 (wool or bud or spear*)).ab,ti.

S6 TX "ear drum*” or eardrum* or tym-

panic

S5 (MH “Tympanic Membrane")

23 (jobson adj3 horn).ab,ti.

24 (chrome adj3 syring*).ab,ti.

S4 (MH "Tympanic Membrane Perfora-

tion")

S3 TX "otitis media" or OME

S2 (MH "Ear+")

S1 (MH "Ear Diseases+")

\section{Appendix 2. Data extraction form}

\begin{tabular}{ll}
\hline REF ID: & Study title: \\
\hline Date of extraction: & Extracted by: \\
\hline
\end{tabular}

Name and email address of correspondence authors:

General comments/notes (internal for discussion):

FLOW CHART OF TRIAL:

Intervention

(name the intervention)

\section{Comparison}

(name the intervention)

No. of people screened

No. of participants randomised - all

No. randomised to each group

Aural toilet (ear cleaning) for chronic suppurative otitis media (Protocol)

Copyright ( 2018 The Cochrane Collaboration. Published by John Wiley \& Sons, Ltd. 
No. receiving treatment as allocated

No. not receiving treatment as allocated

- Reason 1

- Reason 2

No. that dropped out ${ }^{1}$

(no follow-up data for any outcome avail-

able)

No. excluded from analysis ${ }^{2}$ (for all out-

comes)

- Reason 1

- Reason 2

${ }^{1}$ This includes patients who withdrew and provided no data, or did not turn up for follow-up.

${ }^{2}$ This should be the people who were excluded from all analyses (e.g. because the data could not be interpreted or the outcome was not recorded for some reason). This is the number of people who dropped out, plus the people who were excluded by the authors for some reason (e.g. non-compliant).

\section{INFORMATION TO GO INTO THE 'CHARACTERISTICS OF INCLUDED STUDIES' TABLE:}

Methods

$\mathrm{X}$ arm, double-/single-/non-blinded, [multicentre] parallel-group/cross-over/cluster RCT, with x duration of treatment and $\mathrm{x}$ duration of follow-up

Participants

Location: [country, rural?, no. of sites etc.]

Setting of recruitment and treatment: [specialist hospital? general practice? school? state YEAR]

Sample size:

- Number randomised: $x$ in intervention, $y$ in comparison

- Number completed: $x$ in intervention, $y$ in comparison

Participant (baseline) characteristics:

- Age:

- Gender (F/M): number of females (\%)/number of males (\%)

- Main diagnosis: [as stated in paper - state the diagnostic criteria used]

- High risk population: Yes/No

- Cleft palate (or other craniofacial malformation): $y / \mathrm{N}(\%)$

- Down syndrome: $\mathrm{n} / \mathrm{N}(\%)$

- Indigenous groups (Australian Aboriginals/Greenland natives): n/N (\%)

- Immunocompromised: $\mathrm{n} / \mathrm{N}(\%)$

- Diagnosis method [if reported]:

- Confirmation of perforated tympanic membrane: Yes/No/NR or unclear[Method]

- Presence of mucopurulent discharge: Yes/No/NR or unclear - if 'yes', record n/N (\%)

- Duration of symptoms (discharge): $\mathrm{x}$ weeks

- Other important effect modifiers, if data available:

- Alternative diagnosis of ear discharge (where known): $\mathrm{n} / \mathrm{N}(\%)$

- Number who have previously had grommets inserted (and, where known, number where grommets are still in place): $\mathrm{n} / \mathrm{N}(\%)$

- Number who have had previous ear surgery: $\mathrm{n} / \mathrm{N}(\%)$ 


\begin{tabular}{|c|c|}
\hline & $\begin{array}{l}\text { O Number who have had previous antibiotic treatment for CSOM: n/N (\%) } \\
\text { Inclusion criteria: } \\
\text { - [State diagnostic criteria used for CSOM, if available] } \\
\text { Exclusion criteria: }\end{array}$ \\
\hline Interventions & $\begin{array}{l}\text { Intervention }(\mathbf{n}=\mathbf{x}) \text { : drug name, method of administration, dose per day/frequency of administration, } \\
\text { duration of treatment } \\
\text { For aural toileting: who does it, methods or tools used, frequency, duration } \\
\text { Comparator group }(\mathbf{n}=\mathbf{y}) \text { : } \\
\text { Concurrent treatment: } \\
\text { Use of additional interventions (common to both treatment arms): }\end{array}$ \\
\hline Outcomes & $\begin{array}{l}\text { Outcomes of interest in the review: } \\
\text { Primary outcomes: } \\
\text { - Resolution of ear discharge or 'dry ear' (whether otoscopically confirmed or not), measured at } \\
\text { between } 1 \text { week to } 2 \text { weeks, } 2 \text { to } 4 \text { weeks and after } 4 \text { weeks } \\
\text { - Health-related quality of life using a validated instrument (e.g. COMQ-12, COMOT-15, CES) } \\
\text { - Ear pain (otalgia) or discomfort or local irritation } \\
\text { Secondary outcomes } \\
\text { - Hearing, measured as the pure-tone average of air conduction thresholds across } 4 \text { frequencies tested } \\
\text { (at } 500 \mathrm{~Hz}, 1000 \mathrm{~Hz}, 2000 \mathrm{~Hz} \text { and } 4000 \mathrm{~Hz} \text { ), of the affected ear. If this is not available, the pure-tone } \\
\text { average of the thresholds measured. } \\
\text { - Serious complications, including intracranial complications (such as otitic meningitis, lateral sinus } \\
\text { thrombosis and cerebellar abscess) and extracranial complications (such as mastoid abscess, postauricular } \\
\text { fistula and facial palsy), and death. } \\
\text { - Adverse effects from treatment (this will be dependent on the type of treatment reviewed). }\end{array}$ \\
\hline Funding sources & "No information provided"/"None declared"/State source of funding \\
\hline Declarations of interest & "No information provided"/"None declared"/State conflict \\
\hline Notes & $\begin{array}{l}\text { Clinical trial registry no: (if available) } \\
\text { Unit of randomisation: person/ears/other (e.g. cluster-randomised by hospital/school) } \\
\text { [In the case of randomisation by person]: } \\
\text { Methods for including patients with bilateral disease, for example: } \\
\text { - Random selection of one ear as the 'study ear' } \\
\text { - Selecting worse/least affected ear as the 'study ear' } \\
\text { - Counting bilateral ears separately } \\
\text { - Reporting } 2 \text { sets of results (please specify) } \\
\text { - Other (please state) } \\
\text { - Not stated }\end{array}$ \\
\hline
\end{tabular}

\section{RISK OF BIAS TABLE:}

(See table 8.5d in the Cochrane Handbook for Systematic Reviews of Interventions: http://handbook.cochrane.org/). 


\begin{tabular}{lll}
\hline Bias & Authors judgement & Support for judgement \\
\hline $\begin{array}{l}\text { Random sequence generation (selection } \\
\text { bias) }\end{array}$ & High/low/unclear risk & $\begin{array}{l}\text { Quote: “..” } \\
\text { Comment: }\end{array}$ \\
\hline Allocation concealment (selection bias) & High/low/unclear risk & $\begin{array}{l}\text { Quote: “...” } \\
\text { Comment: }\end{array}$ \\
\hline $\begin{array}{l}\text { Blinding of participants and personnel } \\
\text { (performance bias) }\end{array}$ & High/low/unclear risk & $\begin{array}{l}\text { Quote: “...” } \\
\text { Comment: }\end{array}$ \\
\hline $\begin{array}{l}\text { Blinding of outcome assessment (detection } \\
\text { bias) }\end{array}$ & High/low/unclear risk & $\begin{array}{l}\text { Quote: “...” } \\
\text { Comment: }\end{array}$ \\
\hline $\begin{array}{l}\text { Incomplete outcome data (attrition bias) } \\
\text { Selective reporting (reporting bias) }\end{array}$ & High/low/unclear risk & $\begin{array}{l}\text { Quote: “...” } \\
\text { Comment: }\end{array}$ \\
\hline
\end{tabular}

FINDINGS OF STUDY

\section{CONTINUOUS OUTCOMES}

Results (continuous data table)

\begin{tabular}{|c|c|c|c|c|c|c|c|}
\hline \multirow[t]{2}{*}{ Outcome } & \multicolumn{3}{|c|}{$\begin{array}{l}\text { Intervention } \\
\text { (name the intervention) }\end{array}$} & \multicolumn{3}{|c|}{$\begin{array}{l}\text { Comparison } \\
\text { (name the intervention) }\end{array}$} & \multirow{2}{*}{$\begin{array}{l}\text { Other summary statistics/Notes } \\
\text { Mean difference }(95 \% \mathrm{CI}) \text {, P values etc. }\end{array}$} \\
\hline & Mean & SD & $\mathrm{N}$ & Mean & SD & $\mathrm{N}$ & \\
\hline
\end{tabular}

\section{Disease-spe-}

cific health-

related qual-

ity of life

(COMQ-

12, COMOT-

$15, \mathrm{CES})^{1}$

Time point:

(state)

\section{Hearing:}

[Measure-

ment method:

in- 
clude frequencies and report results separately if they are presented in the paper]

Time point: $[\mathrm{xx}]$

\section{Comments:}

[If there is no information apart from (vague) narration, quote here]

[If information is in the form of graphs, used this software to read it: http://arohatgi.info/WebPlotDigitizer/app/, and save a copy of your charts in a folder]

${ }^{1}$ State the measurement method: this will be instrument name/range for patient-reported outcomes.

\section{DICHOTOMOUS OUTCOMES}

Results (dichotomous data table)

\begin{tabular}{|c|c|c|c|c|c|c|}
\hline \multirow[t]{2}{*}{ Outcome } & \multirow{2}{*}{$\begin{array}{l}\text { Applicable } \\
\text { review/ } \\
\text { Intervention }\end{array}$} & \multicolumn{2}{|c|}{ Group A - intervention arm } & \multicolumn{2}{|l|}{ Group B - control } & $\begin{array}{l}\text { Other summary } \\
\text { statistics/Notes }\end{array}$ \\
\hline & & $\begin{array}{l}\text { No. of people } \\
\text { with events }\end{array}$ & $\begin{array}{l}\text { No. of people } \\
\text { analysed }\end{array}$ & $\begin{array}{l}\text { No. of people } \\
\text { with events }\end{array}$ & $\begin{array}{l}\text { No. of people } \\
\text { analysed }\end{array}$ & $\begin{array}{l}\mathrm{P} \text { values, } \mathrm{RR} \\
(95 \% \mathrm{CI}), \mathrm{OR} \\
(95 \% \mathrm{CI})\end{array}$ \\
\hline
\end{tabular}

\section{Resolution of} ear discharge or 'dry ear' at 1 to 2 weeks

[Measurement method or definition used: not/ un-

clear if/otoscopically confirmed] 1

Time

point: [State actual time point]

\section{Resolution of ear discharge or 'dry ear' at 2 to 4 weeks \\ [Measurement}


method or definition used: not/ un-

clear if/otoscopically confirmed]

Time point: [xx]

\section{Resolution}

of ear discharge or 'dry ear' after

4 weeks

[Measurement

method or defi-

nition used: not/

un-

clear if/otoscopically confirmed]

Time point: [xx]

Ear pain/

discomfort/

local irritation

[Measure-

ment method or

definition

used e.g. patient-

reported]

Time point: $[\mathrm{xx}]$

\section{Suspected oto-}

toxicity

[Measure-

ment method or

definition used]

Time point: [xx]

\section{Sensorineural}

hearing loss

[Measure-

ment method or

definition used]

Time point: $[\mathrm{xx}]$

\section{Tinnitus}

[Measure-

ment method or

definition used]

Time point: $[\mathrm{xx}]$ 


\section{Dizziness/ vertigo/balance \\ [Measure- \\ ment method or definition used] \\ Time point: [xx]}

Serious complications:

[State

whether the paper had prespecified looking for this event, how it was diagnosed]

Time point: state length of followup of the trial

Otitic meningi-

tis

[How was this

diagnosed?]

Lateral sinus thrombosis

[How was this diagnosed?]

\section{Cerebellar}

abscess

[How was this

diagnosed?]

\section{Mastoid}

abscess/

mastoiditis

[How was this

diagnosed?]

\section{Postauricular}

fistula

[How was this

diagnosed?]

\section{Facial palsy}

[How was this

diagnosed?]

Note down the page number / table where info was found for ease of checking 


\section{Other compli- \\ cations \\ [How was this \\ diagnosed?]}

\section{Death}

[How was this

diagnosed?]

\section{Multiple se- \\ rious complica- \\ tions \\ [How was this \\ diagnosed?]}

Comment/additional notes:

If any calculations are needed to arrive at the data above, note this down here

${ }^{1}$ State briefly how this was measured in the study, especially whether there was deviation from what was expected in the protocol. For adverse events, note down how these were collected, e.g. whether the adverse event was one of the prespecified events that the study planned to collect, when it was collected and how/who measured it (e.g. as reported by patients, during examination and whether any scoring system was used).

\section{CONTRIBUTIONSOFAUTHORS}

Mahmood F Bhutta: helped to scope, design and write the protocol; clinical guidance at all stages of project scoping and protocol development.

Karen Head: helped to scope, design and write the protocol.

Lee Yee Chong: scoped, designed and wrote the protocol.

Nathan Tu: clinical guidance at all stages of protocol development.

Anne GM Schilder: clinical guidance at all stages of project scoping and protocol development.

Martin J Burton: clinical guidance at all stages of project scoping and protocol development.

Christopher G Brennan-Jones: helped to scope, design and write the protocol; clinical guidance at all stages of project scoping and protocol development. 


\section{DECLARATIONSOF INTEREST}

Mahmood F Bhutta: Mahmood Bhutta has received an honorarium from Novus Therapeutics for advice on an experimental treatment for otitis media (not related to any treatment in this review).

Karen Head: none known.

Lee Yee Chong: none known.

Nathan Tu: none known.

Anne GM Schilder: Professor Anne Schilder is joint Co-ordinating Editor of Cochrane ENT, but had no role in the editorial process for this review. Her evidENT team at UCL is supported in part by the National Institute of Health Research (NIHR) University College London Hospitals Biomedical Research Centre. The research is funded by the NIHR and EU Horizon2020. She is the national chair of the NIHR Clinical Research Network ENT Specialty. She is the Surgical Specialty Lead for ENT for the Royal College of Surgeons of England's Clinical Trials Initiative. In her role as director of the NIHR UCLH BRC Deafness and Hearing Problems Theme, she acts as an advisor on clinical trial design and delivery to a range of biotech companies, most currently Novus Therapeutics.

Martin J Burton: Professor Martin Burton is joint Co-ordinating Editor of Cochrane ENT, but had no role in the editorial process for this review.

Christopher G Brennan-Jones: none known.

\section{SOURCES OF SUPPORT}

\section{Internal sources}

- No sources of support supplied

\section{External sources}

- National Institute for Health Research, UK.

Infrastructure funding for Cochrane ENT

- NHMRC Centre of Research Excellence in Ear and Hearing Health of Aboriginal and Torres Strait Islander Children, Australia. 